\title{
Da crítica à política \\ Tensões entre reconhecimento e democracia racial na política de cotas da Ufrgs
}

\author{
From criticism to politics \\ Tensions between recognition and racial democracy in the \\ quota policy of the Federal University of Rio Grande do Sul, Brazil
}

Luciana Garcia de Mello*

\begin{abstract}
Resumo: Desde os anos 1970, as teorias pós-coloniais vêm denunciando a continuidade das relações de poder e de dominação engendradas durante o período colonial. Ao colocar em questão a universalidade das sociedades Ocidentais, em todos os seus aspectos, mas, sobretudo, em termos políticos e culturais, essa vertente teórica enfatiza a necessidade de inscrição da diferença. Nesse artigo, tem-se por objetivo problematizar a relação entre a crítica pós-colonial e as ações políticas que são adotadas supostamente com o objetivo de promover a diversidade étnico-racial. Adota-se como objeto empírico de investigação o modo de acesso dos estudantes autodeclarados negros na Universidade Federal do Rio Grande do Sul, através do sistema de cotas adotado desde 2007.
\end{abstract}

Palavras-chave: Pós-colonialismo. Antirracismo. Reconhecimento. Democracia Racial.

Abstract: Since the 1970s, post-colonial theories have been denouncing the continuity of the power relations and domination engendered during the colonial period. By calling into question the universality of Western societies in all its aspects, but especially in political and cultural terms, this theoretical approach emphasizes the need to remark difference. In this article, the aim is to problematize the relationship between postcolonial criticism and the affirmative political actions that are adopted with the supposed objective of promoting ethnic-racial diversity. The empirical object of research is the selection process of students who identify themselves as black, allowing them entrance to the Federal University of Rio Grande do Sul in Porto Alegre, Brazil, through the since 2007 adopted quota system.

Keywords: Postcolonialism. Anti-racism. Recognition. Racial democracy.

\footnotetext{
* Doutora em Sociologia pela Universidade Federal do Rio Grande do Sul (Ufrgs, Porto Alegre, RS, Brasil) e pela Université Sophia Antipolis (Unsa, Nice, França), professora do Departamento de Sociologia da Ufrgs. Pesquisadora no Grupo Trabalho e Reconhecimento (Ufrgs) e no Observatório de Gênero da Universidade Federal de Pelotas, RS, Brasil; membro da Comissão da Verdade sobre a Escravidão, da Ordem dos Advogados do Brasil, seção Rio Grande do Sul<lusociais@yahoo.com.br>.
}

Civitas, Porto Alegre, v. 17, n. 2, p. 304-323, maio-ago. 2017 


\section{Introdução}

As abordagens pós-coloniais destinam severas críticas à questão da diferença cultural e às desigualdades existentes nos processos políticos, enfatizando a existência de antinomias e antagonismos no processo de modernização Ocidental. Nessa perspectiva, a continuidade das relações de poder engendradas no período colonial tem-se mostrado um tema recorrente. Isso nos leva a indagar quais são os elementos que viabilizam a manutenção da ordem existente, sobretudo, no que diz respeito às hierarquias raciais. A adoção de ações afirmativas no ensino superior brasileiro é um objeto exemplar para pensar tal questão, dado que é uma medida que inscreve direitos específicos de grupo em uma norma universal e ocidentalizada.

Discute-se nesse artigo, a partir da análise do sistema de cotas da Universidade Federal do Rio Grande do Sul (Ufrgs), a relação entre a crítica pós-colonial e as ações políticas que são adotadas supostamente com o objetivo de promover a diversidade étnico-racial. Na primeira parte do artigo, retoma-se, em linhas gerais, a abordagem pós-colonial; na segunda parte, são apresentados e discutidos os dados quantitativos referentes ao ingresso de estudantes na Ufrgs, através do sistema de cotas destinadas aos egressos de escolas públicas e aos egressos de escolas públicas autodeclarados pretos e pardos. Na parte final do artigo, coloca-se em evidência as tensões existentes entre a ideia de democracia racial e as demandas por reconhecimento da diferença.

\section{Pós-colonialismo, diferença e política}

O termo pós-colonial, como informa Schnapper (1998), foi introduzido por John Rex para descrever a situação das relações raciais no interior das sociedades que anteriormente foram colonizadas e nos antigos países colonizadores. Na concepção de Hall (2006, p. 101), o conceito de póscolonial pode auxiliar a descrever ou caracterizar a mudança nas relações globais, que marca a transição da era dos Impérios para o momento de pósindependência ou da pós-descolonização. O conceito também auxiliaria na identificação das novas relações e disposições do poder que emergem nessa conjuntura. Em termos teóricos, pode-se afirmar que a discussão dessa vertente percorre três campos: 1) referente às condições de formação das sociedades coloniais; 2) referente ao discurso informado por uma determinada orientação epistemológica; 3 ) referente às relações globais, após o período do colonialismo (Kumar, 2000, p. 83). Costa (2006, p. 83) ressalta que não se trata de uma única matriz teórica, mas os diferentes autores que contribuem para essa discussão 
fazem um esforço para esboçar uma referência epistemológica crítica às concepções dominantes de modernidade. Nessa etapa, a crítica pós-colonial é retomada para pensar a relação entre diferença, representação e política, dada a relevância desses temas para o debate sobre o multiculturalismo e a promoção da diversidade.

O pós-colonial procura situar-se dentro de um campo de forças de podersaber através da ruptura com a distinção entre poder e conhecimento. O que está em questão é a recusa da distinção que se faz entre a colonização enquanto um sistema de governo, de poder e de exploração e a colonização enquanto um sistema de conhecimento e representação (Hall, 2006, p. 111). Assim, busca-se evidenciar que a experiência colonial viabiliza a construção de uma determinada narrativa sobre a modernidade e o processo de modernização que estabelece assimetrias entre países - e povos - ocidentais e o resto do mundo. Em um trabalho pioneiro, Said (1990 [1978]) fez uma crítica ao que denominou de orientalismo. Esse conceito diz respeito a uma série de elementos que estão interligados. Na definição do autor, os acadêmicos que ensinam, escrevem ou pesquisam sobre o Oriente são orientalistas e a sua prática científica é denominada de orientalismo. O termo também se refere a um estilo de pensamento que se baseia em uma distinção ontológica e epistemológica entre Ocidente e Oriente. Said chama atenção para o fato de que os termos Ocidente/Oriente não têm estabilidade ontológica, dado que ambos são constituídos de esforço humano, sendo parte afirmação e parte identificação do outro. A questão é que os escritores - poetas, filósofos, teóricos políticos, romancistas, entre outros - têm aceitado essa distinção como ponto de partida para seus trabalhos, sejam eles romances, descrições sociais e mesmo teorias elaboradas não apenas sobre o Oriente, mas também sobre seus povos, costumes e mentalidades. Assim foi estabelecido desde o final do século 18 um movimento totalmente disciplinado - e talvez até regulado - entre o significado acadêmico e o sentido mais ou menos imaginativo da relação Ocidente-Oriente. Nesse sentido,

o Orientalismo pode ser discutido e analisado como a instituição organizada para negociar com o Oriente - negociar com ele fazendo declarações a seu respeito, autorizando opiniões sobre ele, descrevendo-o, colonizando-o, governando-o: em resumo, o orientalismo como um estilo ocidental para dominar, reestruturar e ter autoridade sobre o Oriente (Said, 1990 [1978], p. 15).

Há um esforço do autor em mostrar que o orientalismo consiste numa rede de interesses inevitavelmente aplicados - e assim sempre envolvidos - 
em toda e qualquer ocasião em que essa entidade - o Oriente - é discutida. Ao mesmo tempo, procura mostrar que a cultura europeia ganhou força e identidade ao se contrastar com o Oriente, visto como uma espécie de eu substituto e até subterrâneo. Enquanto Said recorre ao termo orientalismo para falar, sobretudo, de um empreendimento cultural britânico e francês; Stuart Hall, como explica Costa (2006), procura generalizar essa ideia para mostrar que a polaridade entre o Ocidente e o resto do mundo encontra-se na base da constituição das Ciências Sociais. A perspectiva adotada pela sociologia moderna trata as especificidades das sociedades "não ocidentais" como ausência e incompletude, diante do padrão moderno, deduzido unicamente daquelas sociedades que se definiram como ocidentais. A questão é que a distância construída em termos sociais, morais e políticos entre o Ocidente e o "resto" do mundo propiciou a emergência de um regime de representação. Os significados envolvidos nesse sistema de representação tornam-se compreensíveis a partir do conhecimento que se tem sobre quais posições-de-sujeito ele produz e de que modo nós, enquanto sujeitos, podemos ser posicionados em seu interior (Woodward, 2000, p. 18). A representação constrói ao mesmo tempo identidades individuais e coletivas e, enquanto sistema, define os lugares que os indivíduos podem se posicionar; bem como, os locais a partir do qual eles podem falar. Há, portanto, um vínculo entre a produção de significados e a produção das identidades. "Todas as práticas de significação que produzem significados envolvem relações de poder, incluindo o poder para definir quem é incluído e quem é excluído" (Woodward, 2000, p. 19).

O regime de representação não é fechado e mostra-se apto a incorporar novos elementos a sua rede de significados; contudo, mantém um núcleo original de sentidos inalterado, argumenta Hall (1998). Diante disso, a estratégia pós-colonial passa não apenas pela desconstrução da dicotomia Ocidente/ Oriente e pela ruptura com essencialismos e universalismos, mas também pela afirmação da diferença. O conceito diffèrance de Jacques Derrida é retomado para se opor as construções identitárias homogeneizadoras, que aprisionam e localizam a cultura, sublinhando a construção da diferença no processo mesmo de sua manifestação (Costa, 2006, p. 92). A diferença não é pensada como um dado primordial, mas como uma propriedade situada, que emerge em determinados contextos. Para Bhabha (1998), a diferença está relacionada com o hibridismo, permitindo que as diversas posições do sujeito emerjam e torne possível a ressignificação, a reconstrução e a discussão de valores, bem como, mudanças no processo de formação de identidade. Uma vez que o hibridismo vem à tona no campo cultural, ele provoca uma contestação dos símbolos de autoridade, fazendo mudar o terreno dos antagonismos sociais. As polaridades 
existentes nos conflitos que decorrem de visões essencialistas vão sendo substituídas por verdades que são apenas parciais, limitadas e instáveis (Bhabha, 1998, p. 269).

$\mathrm{Na}$ perspectiva pós-colonial, o processo enunciativo tem um valor central, dado que permite trazer o testemunho de países e comunidades que se constituíram de outro modo que não a modernidade. Entra em cena o hibridismo das culturas pós-coloniais, que possuem um modo de se relacionar com a modernidade que pode ser contingente, descontínuo ou mesmo estar em desacordo com esse modelo. Ainda de acordo com Bhabha, essas culturas são construídas num espaço além ou au-delà, isto é, aqui e lá, de todos os lados, sem orientação, desorientado. O além significa um momento de transição; e residir no além é ser parte de um tempo revisionário, um "entre-tempo" que quebra/interrompe/provoca uma pausa na sequência linear da modernidade. A noção de "entre-tempo" está vinculada à ideia de transformar o presente em um lugar expandido e ex-cêntrico de experiência e aquisição do poder, trazendo o passado projetivo. Com isso, o discurso da modernidade,

pode ser inscrito como uma narrativa histórica da alteridade que explora formas de antagonismos e contradição social que ainda não tiveram uma representação adequada, identidades políticas em processo de formação, enunciações culturais no ato do hibridismo, no processo de tradução e transvaloração de diferenças culturais (Bhabha, 1998, p. 347).

Trata-se, portanto de um "entre-tempo" nos símbolos e signos da modernidade, ou seja, nas suas formas de significação e tudo o que é edificado a partir deles. A noção de diferença, explica Bhabha, não deve ser confundida com diversidade, pois a primeira refere-se a um processo de enunciação da cultura como algo conhecível, visando à construção de sistemas de identificação; já a diversidade é um objeto epistemológico. Além disso, a diversidade é uma categoria da ética, da estética ou da etnologia comparativa; já a diferença cultural é um processo de significação através do qual afirmações realizadas sobre a cultura diferenciam, discriminam e autorizam a produção de campos de força, referência, aplicabilidade e capacidade.

Para além da questão da identidade e das formas de construção dos símbolos e do imaginário social, o tema da representação também tem uma dimensão política mais estrita, que se relaciona à participação e à inclusão nos processos políticos. Como explica Young (2006, p. 158), há três modos gerais por meio dos quais as pessoas podem ser representadas: interesses, opiniões e perspectivas. O interesse é definido como aquilo que é importante 
ou afeta os horizontes de vida dos indivíduos; as opiniões dizem respeito aos princípios, valores e prioridades que definem como as coisas são ou como as coisas deveriam ser, impactando, portanto, nos critérios políticos; por fim, as perspectivas levam em consideração as diferentes experiências, histórias e compreensões sociais que são derivadas de um determinado posicionamento na estrutura social. Em relação a esse último aspecto, Young (2006, p. 162) argumenta que "conforme suas posições sociais, as pessoas estão sintonizadas com determinados tipos de significados e relacionamentos sociais, com os quais outras pessoas estão menos sintonizadas". Portanto, há uma compreensão diferenciada de ações, eventos, regras e estruturas, devido ao posicionamento social dos atores; havendo uma tendência dos agentes que estão próximos no espaço social a adotarem perspectivas semelhantes (Young, 2006, p. 162).

No âmbito da formação política e cultural do que Paul Gilroy denomina de Atlântico Negro, há uma crítica à modernidade que adota uma estratégia dupla: "estender a participação dos negros no interior das esferas públicas e das sociedades civis nacionais ao mesmo tempo em que coloca em dúvida a própria legitimidade desse marco político, revelando seus problemas congênitos" (Costa, 2006, p. 118). Diante dessa duplicidade pode-se compreender que o multiculturalismo - referindo-se as estratégias e políticas mobilizadas para governar e/ou administrar questões relacionadas à diversidade e multiplicidade provocadas pelas sociedades multiculturais - é sempre um processo e uma estratégia política inacabada (Hall, 1998, p.50). Como explica o autor, o multiculturalismo ocupa um lugar central no campo da contestação política, pois conduz a uma desestabilização das fundações do estado constitucional liberal. As ideias basilares de cidadania universal e de neutralidade cultural do estado não apenas são criticadas, mas surge uma indagação sobre o seu significado fora do Ocidente e para aqueles que foram socialmente construídos como "o outro". Revela-se assim a contradição entre ideal e prática, entre igualdade formal e igualdade concreta, entre liberdade negativa e liberdade positiva, a partir da perspectiva dos grupos minoritários. Ao mesmo tempo, explicita-se que a neutralidade do estado funciona apenas quando há a pressuposição de uma homogeneidade cultural ampla dos governados (Hall, 1998, p. 74).

A pressão multicultural traz a exigência de que sejam adotadas medidas que levem em consideração as necessidades sociais diferenciadas dos grupos e indivíduos que compõem a Nação. Na perspectiva do multiculturalismo liberal, tal como a de Kymlicka (1996), o estado deve viabilizar a cultura dos grupos minoritários e atuar no combate ao preconceito e à discriminação, 
através de leis antidiscriminatórias, utilização dos meios de comunicação para modificação da imagem, mudanças nas instituições da cultura dominante, entre outras. Porém, para esse autor, não apenas o estado deve se retirar do social, mas as instituições públicas devem manter-se neutras no que diz respeito às relações de poder existentes na sociedade. Já a crítica pós-colonial adota uma postura mais radical e traz à tona a existência de processos de racialização e o esforço para que a questão da raça seja reconhecida na teoria política e no pensamento jornalístico e acadêmico. Há, portanto, um processo permanente de contestação que provoca tensões na política ocidental e nas suas instituições. Apesar da potência dessa crítica, Guillaumin (2002) toca num ponto que é crucial: os processos de resistência apenas parcialmente ocorrem através de canais que são definidos pelos grupos minoritários. O sistema de relações que prevalece é ocidental e, consequentemente, as mudanças provocadas pela emergência dos grupos minoritários convivem com a manutenção da ordem estabelecida. Discutiremos esse paradoxo no item a seguir, adotando como exemplo a política de ações afirmativas da Universidade Federal do Rio Grande do Sul (Ufrgs).

\section{Cotas na Ufrgs: limites e possibilidades da diversidade étnico-racial}

Como discutido no item anterior, o multiculturalismo pode ser compreendido como um processo que, ao pautar a questão da diferença, perturba o discurso e as instituições da modernidade ocidental, abrindo potencial para que as normas e os valores que se tornaram hegemônicos sejam deslocados. Abre-se assim uma disputa que, nessa etapa, será investigada a partir da análise do sistema de cotas adotado pela Ufrgs.

O debate em torno do multiculturalismo no Brasil ganha força na década de 1990, sobretudo durante o segundo mandato do então presidente Fernando Henrique Cardoso, quando esse adotou uma orientação política para mudar a imagem externa do país. Como explica Adorno (2003), na mídia internacional, com frequência era veiculada a imagem do Brasil como um lugar que convive e tolera graves violações aos direitos humanos. Nesse contexto, o governo, que buscava uma maior inserção na política internacional, adotou um conjunto de iniciativas para implementar acordos e convenções internacionais relativas aos direitos humanos. Em 1996, foi criado o I Programa Nacional de Direitos Humanos (PNDH) e definidas três modalidades de ação: a) criação de conselhos de cidadania; b) parcerias com a sociedade civil organizada; c) programas de atendimento especial a grupos sociais discriminados (Adorno, 2003, p. 116). 
Também nesse período foi criado o Grupo de Trabalho Interministerial População Negra (GTI), ${ }^{1}$ formado por militantes dos movimentos negro de diferentes regiões do país e por representação de vários ministérios Saúde, Trabalho, Educação, Relações Exteriores, Esportes, Justiça, Cultura e Planejamento - além de Secretarias de Comunicação Social e de Assuntos Estratégicos. Esse grupo de trabalho desenvolveu uma série de ações no âmbito do governo federal e deu início a uma importante reflexão sobre as políticas de ação afirmativa. ${ }^{2}$

Durante a criação do GTI, o presidente Fernando Henrique Cardoso adotou uma postura bastante progressista e enfatizou a necessidade de modificar o quadro de discriminação por cor, bem como de encontrar mecanismos e processos capazes de tornar a relação entre raças, grupos sociais e entre as classes sociais mais democráticas (Rios, 2012, p. 65). Todavia, apesar dessas importantes mudanças no modo como o estado brasileiro historicamente vinha se posicionando em relação à questão racial, a adoção de políticas afirmativas, entre elas as cotas nas universidades, teve início somente após a realização da III Conferência Mundial contra a discriminação racial, o racismo, a xenofobia e a intolerância correlata, ocorrida em 2001, em Durban, na África do Sul. Ribeiro (2014) esclarece que a Declaração e o Programa de Ação de Durban (DDPA), assim como as estruturas criadas para o seu acompanhamento, estimularam os estados signatários a adotarem medidas para implementação de políticas de igualdade racial. A partir de então foi possível identificar uma resposta ativa, através da criação e/ou potencialização de órgãos governamentais dedicados ao tratamento das questões raciais nos países latinos.

Nos anos 2000 começa a ser adotada, de forma descentralizada, a política de cotas no ensino superior brasileiro. Inicialmente, entre 2002 e 2007, essa modalidade de ação afirmativa foi adotada pelas universidades estaduais, destacando-se o pioneirismo da Universidade do Estado do Rio de Janeiro (Uerj); em 2008, com a criação do Programa de Apoio ao Plano de Reestruturação e Expansão das Universidades Federais (Reuni), o governo federal estimulou a adesão a esse sistema e diversas instituições federais também estabeleceram cotas. Por fim, em 2012 foi promulgada a lei federal

\footnotetext{
${ }^{1}$ Conforme Ivair Alves dos Santos, esse grupo já estava sendo gestado dentro do Ministério da Justiça para que se construísse as bases para discutir as ações afirmativas. Ivair destaca que o GTI foi uma proposta do governo e não uma conquista da sociedade civil (Rios, 2012, p. 63). Todavia, é importante destacar que é uma conquista de ativistas do movimento negro que já pertenciam à estrutura do estado.

${ }^{2}$ Em 1996 foi realizado o Seminário Multiculturalismo e Racismo - o papel das ações afirmativas nos Estados democráticos contemporâneos.
} 
que regulamenta a política e a torna obrigatória (Feres Jr., Daflon, 2014). Adotando-se a discussão de Hall sobre o multiculturalismo, pode-se afirmar que a reserva de vagas nas universidades provoca pelo menos dois importantes efeitos transruptivos, que perturbam e deslocam o discurso hegemônico. Em primeiro lugar, tem-se uma modificação na forma de atribuição de direitos, pois, ainda que o estado moderno ofereça garantias ao conjunto de cidadãos, esses devem ser vistos como formas de proteção individual. Já o multiculturalismo apresenta uma reivindicação por proteção a determinados grupos e implica em atribuição de um direito coletivo. Em segundo lugar, essas políticas estão relacionadas ao reconhecimento oficial do racismo por parte do estado, que até meados da década de 1970 não titubeava em enfatizar a harmonia das relações raciais no Brasil. Tem-se assim o surgimento de outro quadro cognitivo para a construção de políticas, no qual há uma intersecção entre o princípio normativo da igualdade e a exigência da diferença.

As cotas devem ser compreendidas como uma importante vitória da luta antirracista, que, desde os anos 1930, reivindicava o direito à educação. Essa pauta já estava presente na Frente Negra Brasileira, uma das organizações pioneiras do movimento negro pós-abolição; e, em 1945, o Teatro Experimenta Negro (TEN), sob a liderança de Abdias do Nascimento, já reivindicada a admissão subvencionada de estudantes negros nas instituições de ensino secundário e superior (A. Nascimento; E. Nascimento, 2000, p. 210). Cumpre sublinhar que há um importante descompasso entre a demanda dos movimentos negros e o modo como a reserva de vagas foi implementada. Se, por um lado, em nome da igualdade adotou-se um direito coletivo; por outro, esse princípio foi interpretado com um viés nitidamente classista. De acordo com Daflon et al. (2013), os alunos oriundos de escola pública se destacam como os principais beneficiários dessa política: $85 \%$ das universidades que adotam reserva de vaga, bonificação ou acréscimo de vaga, visam a esse grupo; $58 \%$ focalizam pretos e pardos; $51 \%$ têm os indígenas como público-alvo. Portadores de deficiências, pessoas com baixa renda, entre outros, também são beneficiados pela política.

A Universidade Federal do Rio Grande do Sul, objeto dessa discussão, apesar de ter adotado desde o início o modelo de cotas mistas, tratou de estabelecer um compromisso com a promoção da diversidade étnico-racial. A Decisão 134/07 do Conselho Universitário (Consun) aprovou a adoção do Programa de Ações Afirmativas com os seguintes objetivos:

I - ampliar o acesso em todos os cursos de graduação e cursos técnicos oferecidos pela Ufrgs para candidatos egressos do Sistema Público de Ensino Fundamental e Médio e para candidatos autodeclarados 
negros egressos do Sistema Público de Ensino Fundamental e Médio, mediante habilitação no concurso vestibular e nos processos seletivos dos cursos técnicos;

II - promover a diversidade étnico-racial e social no ambiente universitário;

III - apoiar estudantes, docentes e técnicos administrativos para que promovam, nos diferentes âmbitos da vida universitária, a educação das relações étnico-raciais;

IV - desenvolver ações visando a apoiar a permanência, na Universidade, dos alunos referidos no artigo primeiro mediante condições de manutenção e de orientação para o adequado desenvolvimento e aprimoramento acadêmico-pedagógico.

No plano retórico, é inquestionável que a diversidade tornou-se um mecanismo de regulação do princípio da igualdade.

A primeira fase do sistema de cotas foi executada entre 2008 e 2012, havendo uma reserva de $30 \%$ do total de vagas do concurso vestibular para estudantes de escolas públicas e dentro desse percentual, 50\% para estudantes autodeclarados negros. ${ }^{3}$ Houve também a criação de 10 vagas anuais para estudantes indígenas, que foram preenchidas através de processo seletivo específico. O relatório de avaliação da implementação do programa, nessa primeira fase, revela o aumento significado do número de classificados egressos de escolas públicas em todos os cursos de graduação da Ufrgs, passando de 31,53\% em 2007 (último vestibular sem cotas) para 49,87\% já em 2008. Em relação aos estudantes autodeclarados negros, o percentual de classificados passou de 3,27\% em 2007 para 11,03\% em 2008.

Ainda que esses números sejam expressivos, é importante sublinhar que nem todas as vagas ofertadas para os candidatos egressos do ensino público autodeclarado negro foram ocupadas, ${ }^{4}$ como pode ser observado no Quadro 1.

As vagas não ocupadas pelos candidatos autodeclarados negros são deslocadas para os estudantes de escola pública para garantir que o percentual de reserva seja efetivo. Persistindo a ociosidade, elas são deslocadas para o acesso universal. A maior parte das vagas destinadas à cota racial, que ficam vagas, de fato acaba sendo preenchida pelos egressos de escola pública. Contudo, cumpre destacar que em todos os anos listados acima, os candidatos

\footnotetext{
${ }^{3}$ Utilizar-se-á o termo negro para designar indivíduos pretos e pardos.

${ }^{4}$ Não significa que apenas esse número de candidatos negros foi aprovado, mas sim que esse número ingressou pelas cotas raciais. Todos os candidatos concorrem inicialmente no sistema universal.
} 
que optaram pelo acesso universal também foram beneficiados pelas vagas remanescentes dos cotistas negros. Consequentemente, o número de vagas ocupadas por esses estudantes foi sempre superior ao número de vagas inicialmente ofertadas.

Quadro 1. Número de inscritos, vagas ofertadas e vagas ocupadas no vestibular da Ufrgs, conforme modalidade de ingresso - 2008-2012

\begin{tabular}{|c|l|r|r|r|}
\hline \multirow{2}{*}{ Ano } & $\begin{array}{c}\text { Inscritos } \\
\text { e vagas }\end{array}$ & Universal & Ensino público & $\begin{array}{c}\text { Ensino público } \\
\text { autodeclarado } \\
\text { negro }\end{array}$ \\
\hline \multirow{3}{*}{2008} & Inscritos & 23.470 & 10.173 & 1.356 \\
\cline { 2 - 5 } & Vagas ofertadas & 2.978 & 667 & 667 \\
\cline { 2 - 5 } & Vagas ocupadas & 2.997 & 1.020 & 295 \\
\hline \multirow{3}{*}{2009} & Inscritos & 22.785 & 10.341 & 1.427 \\
\cline { 2 - 5 } & Vagas ofertadas & 3.148 & 704 & 704 \\
\cline { 2 - 5 } & Vagas ocupadas & 3.174 & 1.151 & 231 \\
\hline \multirow{3}{*}{2010} & Inscritos & 20.802 & 10.564 & 1.340 \\
\cline { 2 - 5 } & Vagas ofertadas & 3.419 & 771 & 771 \\
\cline { 2 - 5 } & Vagas ocupadas & 3.468 & 1.246 & 247 \\
\hline \multirow{3}{*}{2012} & Inscritos & 23.045 & 11.760 & 1.509 \\
\cline { 2 - 5 } & Vagas ofertadas & 3.460 & 779 & 779 \\
\cline { 2 - 5 } & Vagas ocupadas & 3.514 & 1.239 & 265 \\
\hline \multirow{2}{*}{} & Inscritos & 25.087 & 13.957 & 1.934 \\
\cline { 2 - 5 } & Vagas ofertadas & 3.650 & 820 & 820 \\
\cline { 2 - 5 } & Vagas ocupadas & 3.715 & 1.141 & 407 \\
\hline \multirow{2}{*}{} & & & & \\
\hline \multirow{2}{*}{} & & & & \\
\hline
\end{tabular}

Fonte: <www.coperse.ufrgs.br>

No primeiro vestibular com cotas, realizado em 2008, diversos cursos não recrutaram sequer um aluno autodeclarado negro, que tenha realizado inscrição nessa modalidade. Assim, cursos como Administração, Direito diurno, Biomedicina, Fonoaudiologia, Engenharia Ambiental, Relações Internacionais, Medicina, entre outros, na prática não vivenciaram a experiência das ações afirmativas. Entre os anos de 2008 e 2011, somente três candidatos ingressaram através das cotas raciais no curso de Medicina. ${ }^{5}$

\footnotetext{
${ }^{5}$ Fonte: Relatório Anual do Programa de Ações Afirmativas, 2013-2014 e <www.coperse. ufrgs.br>.
} 
Em agosto de 2012 foi aprovada a Decisão 268 que determina a continuidade do programa de ações afirmativas na Ufrgs por mais dez anos. Mais uma vez a proposição de cotas raciais estabelecidas independentemente da origem escolar dos indivíduos negros acabou sendo derrotada. Também não obteve êxito a proposta de aumento de $30 \%$ para $50 \%$ na reserva de vagas. Todavia, no mesmo ano foi aprovada em outubro a Lei Federal 12.711 - conhecida como Lei de Cotas - que padroniza a reserva de vagas para estudantes egressos do ensino público para todas as universidades e institutos federais. Essa lei provocou uma mudança significativa no sistema até então adotado pela Ufrgs, pois possibilita que as pessoas que realizaram o ensino fundamental em escolas particulares possam concorrer pelas cotas, desde que tenham cursado todo o ensino médio em escola pública. Ocorreu também outra mudança importante no modo de ingresso: até o concurso vestibular de 2013, todos os candidatos concorriam inicialmente pelo acesso universal, mas a partir de 2014, a universidade passou a contar com dois sistemas um exclusivamente universal e outro universal com reserva de vagas. Assim, o candidato que optar por esse segundo sistema deve indicar uma das quatro modalidades da reserva de vaga: a) RA - estudantes egressos de escola pública, com renda familiar igual ou inferior a 1,5 salários mínimos per capita; b) RB - estudantes egressos de escola pública, autodeclarados pretos, pardos ou indígenas, com renda familiar igual ou inferior a 1,5 salários mínimos per capita; c) RC - estudantes egressos de escola pública, com renda familiar igual ou superior a 1,5 salários mínimos per capita; d) RD - estudantes egressos de escola pública, autodeclarados pretos, pardos ou indígenas, com renda familiar igual ou superior a 1,5 salários mínimos per capita. Essas modalidades foram definidas pela Lei de Cotas, sendo que no caso das cotas raciais a distribuição observa a proporção de pretos, pardos e indígenas em cada estado.

Em relação ao percentual de vagas, ficou estabelecido pela Lei de Cotas que até 2016 todas as instituições federais de ensino superior deveriam reservar, no mínimo, $50 \%$ do total de vagas em todos os cursos e turnos de graduação. Na Ufrgs, a reserva aumentou para $40 \%$ no concurso vestibular de 2015 e, no ano seguinte, atingiu o percentual definido pela lei. Houve um expressivo aumento no número de inscritos no primeiro vestibular após a aprovação da Lei Federal. O número passou de 40.978 em 2012 para 46.244 no ano seguinte. A ampliação ocorreu na modalidade de acesso pelas cotas; já o número de inscritos pelo acesso universal não sofreu variação expressiva, indicando que havia uma demanda reprimida em razão da exigência de que o candidato tivesse realizado metade de seu ensino fundamental em escola 
pública $^{6}$. Assim, em 2012, o número de candidatos inscritos pelo sistema universal foi de 25.087 e no ano de 2013, 25.309; inscritos pela reserva de escola pública em 2012 eram 13.957 e, no ano seguinte, 17.747, representando um aumento de $27 \%$. A transformação mais significativa foi entre os inscritos na reserva de escola pública autodeclarados pretos, pardos e indígenas: em 2012 houve 3188 candidatos contra 1934 no ano anterior, o que significa um aumento de quase $65 \% .^{7}$ Por outro lado, a divisão por renda, permite constatar que há uma menor procura por parte das pessoas que têm rendimento inferior a 1,5 salários mínimos. Entre os inscritos no vestibular de 2013: 54,6\% universal, $34,6 \%$ reserva não baixa renda e $10,8 \%$ reserva baixa renda. Como afirmam Daflon et al. (2013, p.313), "o acesso à educação superior demanda um acúmulo mínimo de recursos econômicos e culturais". Os autores postulam que não é razoável supor que a política de cotas vai beneficiar os mais pobres entre os pobres. Em sentido semelhante, Beltrão e Teixeira (2004), consideram que o vestibular é uma seleção de selecionados. No momento da inscrição, os candidatos escolhem suas carreiras dentro de suas possibilidades individuas e, em seguida, o exame trata de fazer uma nova seleção entre os candidatos préselecionados na primeira etapa.

Do ponto de vista da diversidade étnico-racial, houve importantes avanços redistributivos, desde a implementação das cotas até o momento atual. Se em 2008 os candidatos pretos e pardos ocuparam $44,2 \%$ das vagas que lhes foram destinadas, e nos anos seguintes o percentual foi semelhante; a partir de 2012 passou a ocorrer um aumento gradativo. O percentual de ocupação foi de 49,6\% em 2012; 74,1\% em 2013; e 77,9\% em 2014. O maior aproveitamento de vagas pode ser explicado em grande medida pela modificação nas normas até então vigentes no concurso vestibular. Até o ano de 2011, o critério utilizado para corrigir as redações tinha por parâmetro todos os candidatos, independentemente de suas modalidades de inscrição. Desse modo, para estabelecer o número de redações a serem corrigidas, multiplicava-se o número total de vagas em cada curso por quatro, ficando a nota do candidato localizado nessa posição estabelecida como ponto de corte para uma classificação prévia. Todos os candidatos que obtivessem nota inferior eram automaticamente eliminados. Uma vez que o desempenho dos estudantes cotistas no vestibular tem-se mostrado inferior ao dos estudantes que se inscrevem pelo sistema universal, a adoção de uma nota de corte estabelecida com referência a esses últimos mostrou-se bastante prejudicial aos candidatos da reserva de vaga.

\footnotetext{
${ }^{6}$ Fonte: Relatório Anual do Programa de Ações Afirmativas, 2013-2014.

${ }^{7}$ Não há evidência de que candidato indígena tenha se inscrito.
} 
Desde o vestibular de 2012, o número passou a ser definido em relação às vagas disponíveis em cada modalidade de ingresso, distinguindo-se assim os candidatos do acesso universal dos candidatos cotistas e entre esses os cotistas brancos dos não-brancos.

Para além do aumento de candidatos aprovados no vestibular, houve um significativo aumento de cursos que tiveram todas as vagas ofertadas efetivamente preenchidas pelos candidatos autodeclarados negros. Em 2008, apenas 5 cursos tiveram a classificação total: licenciatura em educação física, licenciatura em física, geografia, enfermagem e engenharia cartográfica. Com exceção desse último, pode-se afirmar que são cursos majoritariamente procurados por pessoas de baixa renda e por mulheres. Nos anos seguintes, manteve-se semelhante o número de cursos com ocupação total e o perfil no que diz respeito aos alunos e a valorização social. Exceção deve ser feita ao curso de Psicologia, que possui acentuada valorização social e teve as vagas totalmente ocupadas já em 2009. No ano de 2012, o número de curso com ocupação total passou para 20; em 2013, para 28 e em 2014 para 41. No último concurso vestibular, realizado em 2017, apenas 10 cursos - de um total de 90 , não tiveram candidatos aprovados na modalidade de reserva para estudantes egressos de escola pública, autodeclarados pretos, pardos ou indígenas, com renda familiar igual ou superior a 1,5 salários mínimos per capita. ${ }^{8}$

Os méritos alcançados pelo sistema de cotas, em relação ao ingresso, são inquestionáveis. Todavia, tendo por referência a análise precedente, podese concluir que a não aprovação de cotas estritamente raciais é um fator que retarda a promoção da diversidade étnico-racial na universidade. Esse elemento está relacionado a uma interpretação restritiva do princípio da igualdade, que restringe o seu significado a uma dimensão classista e desconsidera as múltiplas formas de produção de diferenças e hierarquias entre os indivíduos. A intersecção entre a diferença e o princípio da igualdade é um processo que está sendo construído no sistema de cotas atualmente vigente, a partir de uma série de deslocamentos que se tornam possível em razão das incongruências que essa política apresenta.

Deve-se ainda ter em consideração que a não inclusão dos candidatos autodeclarados negros egressos das escolas privadas faz com que haja no meio acadêmico, predominantemente, a interação de indivíduos brancos de classes sociais mais abastadas com indivíduos não-brancos das classes sociais menos favorecidas. Isso cria uma relação naturalmente hierárquica dado que tanto as diferenças de status socioeconômico quanto o pertencimento racial têm

\footnotetext{
${ }^{8}$ Fonte: <www.coperse.ufrgs.br>
} 
importância crucial para as relações de reconhecimento. O caso estudado também evidencia os limites de construção de uma política voltada para o multiculturalismo que se inscreve em um molde universal.

\section{Tensões entre democracia racial e reconhecimento}

Ativistas e militantes das entidades do movimento negro favoráveis à adoção de ações afirmativas obtiveram uma importante vitória com a implementação do sistema de cotas nas universidades. No entanto, na disputa que se estabeleceu, não foi possível evitar que o problema do racismo tenha sido de algum modo minimizado. Duas ideias estão subjacentes ao sistema de reserva de vagas que acabou sendo implementado: 1) a de que o pertencimento racial e/ou a cor não interferem nas oportunidades dos indivíduos mais bem posicionados na estrutura social; 2) e a de que os desiguais resultados atingidos pelos grupos resultam exclusivamente de oportunidades também desiguais. Ocorre que as desigualdades raciais não são fruto apenas de diferenças objetivas, que podem ser minimizadas somente com a redistribuição de oportunidades sociais, tal como ocorre com essa medida.

Ainda que a política de cotas seja imprescindível, resta ainda o desafio de que os indivíduos negros sejam igualmente reconhecidos. Axel Honneth (2003; 2014), ao tratar o reconhecimento como algo necessário para a autonomia individual, nos remete à questão sobre as possibilidades de construção de relações de reciprocidade entre os indivíduos em diferentes áreas sociais. Para o autor, os diversos padrões de reconhecimento estão vinculados a relações intersubjetivas e à existência de um meio social favorável, que possibilite mudanças valorativas capazes de tornar a ordem social mais justa (Honneth, 2014). Essa mudança é tolhida na sociedade brasileira tanto pela existência de uma forte assimetria racial quanto pela persistência do mito da democracia racial.

A realidade social da raça está estritamente associada a uma ordem societária em que prevalece uma distinção hierárquica entre indivíduos brancos e não brancos. Em sentido estrito, o conceito de raça não possui qualquer valor explicativo para a realidade social ou para as relações entre as pessoas. No entanto, raça é um conceito que ganha significado em processos sociais, econômicos, culturais e psicológicos, e tem um caráter relacional (Fanon, 1952). Nesse sentido, esse marcador social pode ser equiparado a um capital simbólico, assim compreendido como um capital percebido de acordo com elementos que integram o sistema simbólico, tais como categorias de percepção, princípios de visão e de divisão, sistemas de classificação, esquemas 
cognitivos e classificatórios (Bourdieu, 1996; 2003). Esse sistema se organiza de acordo com a mesma lógica do espaço social, isto é, segundo o princípio da diferença e do desvio diferencial, e constrói distinções significantes. Ainda segundo Bourdieu, mais do que a realidade das categorias de apreciação e de classificação, importa sua eficácia prática.

A raça é um capital que permite estabelecer distâncias significativas, pois ela opera em consonância com o racismo, que é um sistema de dominação assente na afirmação da diferença. O racismo oprime os indivíduos, impedindo-os de participar de forma igualitária na sociedade e estabelecendo segregações; já os processos de racialização conformam o imaginário e as visões de mundo, naturalizando os mecanismos de opressão social. Uma das consequências desse processo é que as desigualdades raciais ficam subsumidas em ideologias igualitárias e de meritocracia. Na sociedade brasileira, temos ainda o mito da democracia racial que com sua veemente negação da diferença colabora para a manutenção da ordem social. Ainda que venha sendo fortemente atacado por intelectuais e militantes dos movimentos negros, ao menos desde os anos 1970, a persistência desse ideário parece ser inquestionável. Essa perpetuação, em parte, pode ser explicada pelas verdades que o mito produz. É preciso reconhecer que a ideia de democracia racial é um elemento constitutivo da nossa identidade nacional. Na década de 1930, quando se começa a discutir o Brasil enquanto nação e a identidade do povo, como explica Wade (2000, p.62), definir o que significava ser brasileiro não se relacionava apenas a uma questão introspectiva, mas dizia respeito também a uma representação no cenário internacional. Ainda segundo o autor, a comparação estabelecida por Gilberto Freyre entre Brasil e Estados Unidos tinha por finalidade construir uma autoimagem que enfatiza a um só tempo a mestiçagem e a tolerância. Em consonância com essa interpretação, ao colocar em discussão as raízes do Brasil, Sérgio Buarque de Holanda tratou de destacar as especificidades do temperamento do homem brasileiro, que teria a cordialidade como marca característica. Faz-se necessário explicitar o sentido do termo "homem cordial".

O 'homem cordial' não pressupõe bondade, mas somente o predomínio dos comportamentos de aparência afetiva, inclusive suas manifestações externas, não necessariamente sinceras nem profundas, que se opõem ao ritualismo da polidez. O 'homem cordial' é visceralmente inadequado às relações impessoais que decorrem da posição e da função do indivíduo, e não da sua marca pessoal e familiar, das afinidades nascidas nas intimidades dos grupos primários (Candido, 1995, p. 17). 
A cordialidade por sua vez, no entendimento de Holanda (1995), seria a contribuição brasileira para a civilização. Esse traço da personalidade tem um papel crucial para a afirmação da ideia de democracia racial: a cordialidade teria possibilitado a solução dos problemas raciais de modo democrático, dado que permite a convivência pacífica e a consequente assimilação dos grupos negros e indígenas. "O mito das três raças, ao se difundir na sociedade, permite aos indivíduos, das diferentes classes sociais e dos diversos grupos de cor, interpretar, dentro do padrão proposto, as relações raciais que eles próprios vivenciam" (Ortiz, 2006, p. 43).

A persistência do mito também pode ser compreendida pelo processo de apropriação das manifestações culturais da população negra, tal como o samba. Como observa Ortiz (2006), o samba de fato se tornou um símbolo de brasilidade, o que revela que a utilização da cultura como um elemento para construir uma identidade nacional mestiça obteve êxito. Em contrapartida, isso contribui para as dificuldades em discernir as fronteiras de cor. Para além disso, essa apropriação criou um espaço de proximidade e de convivência entre brancos e não-brancos e entre diferentes classes sociais. Hasenbalg (1998) considera que há áreas moles nas relações raciais, tais como o futebol, o bar, os espaços religiosos e de lazer, em que o fato de ser negro não faz muita diferença; e áreas duras, como o mercado de trabalho e a escola, em que as assimetrias são fortemente marcadas. Um dos papéis das áreas moles é justamente "reforçar as imagens da 'cordialidade brasileira', da fluidez e brandura das relações raciais no país" (Hasenbalg, 1998, p. 16-17).

A grande magia do mito da democracia racial consiste não em negar o racismo, mas deslocá-lo para o âmbito das relações privadas. Em pesquisa realizada pelo Instituto Datafolha, 91\% dos entrevistados afirmaram que os brasileiros brancos têm preconceito de cor em relação aos negros. ${ }^{9}$ No entanto, há uma "meia verdade" nesse processo de reconhecimento. Ao mesmo tempo em que atitudes e práticas cotidianas de discriminação racial são identificadas; a dimensão estrutural e política do racismo é impetuosamente negada. Reis (2004) realizou uma pesquisa sobre a percepção das elites e do povo sobre a desigualdade e constatou que para ambos a pobreza e a desigualdade social são considerados problemas de grande importância. Porém, a definição das elites de igualdade é igualdade de oportunidades e embora exista amplo consenso quanto à existência de preconceito de cor e gênero no Brasil, há

\footnotetext{
${ }_{9}$ A pesquisa ouviu 2.982 pessoas em 213 municípios. A margem de erro é de 2 pontos percentuais para mais ou para menos. Esse levantamento, realizado em 2008, repete perguntas realizadas em 1995 pelo mesmo instituto. Fonte: <http://www1.folha.uol.com.br/fsp/especial/fj2311200801. htm> (24 mar. 2017).
} 
também concordância entre as elites que exercer discriminação positiva para compensar segmentos sociais discriminados não constitui solução adequada (Reis, 2004, p. 48). Em pesquisa mais recente, também realizada pelo Instituto Datafolha, 65\% da população brasileira declarou ser favorável à adoção de ações afirmativas para negros nas universidades; já o percentual de apoio às cotas para pessoas pobres e de renda baixa sobe para 87\% (Queiroz e Santos, 2006, p. 718). Esses dados mais uma vez revelam a dificuldade em perceber o impacto do racismo na vida cotidiana das pessoas.

Dada à existência de um trabalho permanente de inculcação do mito da democracia racial, a luta antirracismo encontra sérias dificuldades para intervir nos processos econômicos, políticos e sociais, que viabilizam a produção e a reprodução das desigualdades raciais. Ainda que os brasileiros concordem com a existência de racismo; os seus efeitos e o seu modo de funcionamento permanecem opacos. Essa opacidade é um obstáculo para promoção da justiça social.

\section{Considerações finais}

Desde a promulgação da Constituição Federal de 1988 tem havido um maior reconhecimento da questão racial no Brasil. Há uma série de avanços que vão desde a criminalização do racismo, a definição jurídica da figura do remanescente de quilombo; passando pela criação de diversos órgãos e secretárias estatais voltadas para o combate ao racismo e a promoção da igualdade racial, culminando com a adoção do sistema de cotas nas universidades. Ocorre que essas mudanças, ainda que tenham obtido resultados favoráveis, defrontam-se, por um lado, com um rígido sistema de opressão racial, e de outro, com um processo histórico de racialização, que possui uma incrível capacidade de atualização e adaptação a diferentes configurações.

Além disso, seja porque o racismo estrutura a ordem social brasileira, seja porque ele fica na ordem do impensável, não se produz um meio social favorável para a institucionalização de valores não-racistas. Diante disso, ainda que sejam adotadas políticas para promover a diversidade, há um descompasso entre ideal e prática, que acaba por retardar a promoção da igualdade racial. Não por acaso, os coletivos de estudantes negros da Ufrgs adotam o slogan: Cota é gota!

\section{Referências}

ADORNO, Sérgio. Lei e ordem no segundo governo FHC. Tempo Social, São Paulo, v. 15 , n. 2, p. 103-140, $2003<10.1590 /$ S0103-20702003000200005>. 
BELTRÃO, Kaizô; TEIXEIRA, Moema de Poli. O vermelho e o negro: raça e gênero na universidade brasileira - uma análise da seletividade das carreiras a partir dos censos demográficos de 1960 a 2000. Rio de Janeiro: Ipea. Texto para discussão, n. 1052, outubro, 2004.

BHABHA, Homi K. O local da cultura. Belo Horizonte: UFMG, 1998.

BOURDIEU, Pierre. O poder simbólico. São Paulo: Bertrand, 2003.

BOURDIEU, Pierre. Razões práticas: sobre a teoria da ação. Campinas: Papirus, 1996.

CANDIDO, Antônio. O significado de raízes do Brasil. In: Sérgio Buarque de Holanda. Raízes do Brasil. São Paulo: Cia. das Letras, 1995. p.9-23.

COSTA, Sérgio. Dois Atlânticos: teoria social, anti-racismo, cosmopolitismo. Belo Horizonte: Editora UFMG, 2006.

DAFLON, Verônica T.; FERES JUNIOR, João; CAMPOS, Luiz A. Ações Afirmativas raciais no ensino superior público brasileiro: um panorama analítico. Cadernos de Pesquisa, v. 43, n. 148, p. 302-327, $2013<10.1590 /$ S0100-15742013000100015>.

FANON, Frantz. Peau noire, masques blancs. Paris: Éditions du Sueil, 1952.

FERES JUNIOR, João; DAFLON, Verônica T. Políticas da igualdade racial no ensino superior. Cadernos do Desenvolvimento Fluminense, n. 5, p. 3-43, 2014.

GUILLAUMIN, Colette. L'idéologie raciste: gènese et langage actuel. Paris: Gallimard, 2002.

HALL, Stuart. A identidade cultural na pós-modernidade. Rio de Janeiro: DP\&A, 1998.

HALL, Stuart. Questão multicultural. In: Da diáspora: Identidades e mediações culturais. Belo Horizonte: UFMG; Brasília: Representações da Unesco no Brasil, 2006. p. 51-100.

HASENBALG, Carlos A. Relações raciais no contexto nacional e internacional. In: Carlos A. Hasenbalg; Kabengele Munanga; Lilia Schwarcz M. (Org.). Racismo: perspectivas para um estudo contextualizado da sociedade brasileira. Niterói: Eduff, 1998.

HOLANDA, Sérgio Buarque de. Raízes do Brasil. São Paulo: Cia. das Letras, 1995.

HONNETH, Axel. El derecho de la libertad: esbozo de una eticidad democrática. Madrid: Katz, 2014.

HONNETH, Axel. Luta por reconhecimento: a gramática social dos conflitos sociais. São Paulo: Editora 34, 2003.

KUMAR, Margaret. Postcolonial theory and cross-culturalism: collaborative "signposts" of discursive pratices. Journal of Educational Enquiry, v. 1, n. 2, p. 83-92, 2000.

KYMLICKA, Will. Ciudadanía multicultural: una teoría liberal de los derechos de las minorías. Barcelona: Paidós, 1996.

NASCIMENTO, Abdias; L. NASCIMENTO, Elisa. Reflexões sobre o movimento negro no Brasil, 1938-1997. In: Lynn Huntley; Antônio Sérgio A. Guimarães (Org.). Tirando a máscara: ensaios sobre o racismo no Brasil. São Paulo: Paz e Terra, 2000. p. 203-236. 
ORTIZ, Renato. Cultura brasileira e identidade nacional. São Paulo: Brasiliense, 2006.

QUEIROZ, Delcele M.; SANTOS, Jocélio T. Sistemas de cotas: um debate - dos dados à manutenção do privilégio e de poder. Educação e Sociedade, Campinas, v. 27, n. 96 (Especial), p. 717-737, 2006.

REIS, Elisa. A desigualdade na visão da elite e do povo brasileiro. In: Celi Scalon, (Org.). Imagens da desigualdade. Belo Horizonte: Ed. UFMG, 2004. p. 37-73.

RIBEIRO, Matilde. Políticas de promoção da igualdade racial no Brasil (1986-2010). Rio de Janeiro: Garamond, 2014.

RIOS, Flávia. O protesto negro no Brasil contemporâneo (1978-2010). Lua Nova, São Paulo, n. 85, p. 41-79, 2012

SAID, Edward W. Orientalismo: o Oriente como invenção do Ocidente. São Paulo: Cia. das Letras, 1990.

SCHNAPPER, Dominique. La relation à l'autre: au coeur de la pensée sociologique. Paris: Gallimard, 1998.

UNIVERSIDADE Federal do Rio Grande do Sul. Relatório anual do programa de ações afirmativas. Coordenadoria de Acompanhamento do Programa de Ações Afirmativas, 2014.

UNIVERSIDADE Federal do Rio Grande do Sul. Relatório do acompanhamento quantitativo do ingresso de estudantes no âmbito da politica de reserva de vagas da UFRGS no periodo de 2008-2012.

UNIVERSIDADE Federal do Rio Grande do Sul/Conselho Universitário. Decisão $n$ o 134 de 19 de junho de 2007. Institui o Programa de Ações Afirmativas, através do Ingresso por Reserva de Vaga para o Acesso de todos os cursos de graduação e cursos técnicos da Universidade Federal do Rio Grande do Sul. Porto Alegre: Ufrgs, 2007.

WADE, Peter. Raza y etnicidad en latinoamerica. Quito: Ediciones Abya-Ayala, 2000.

WOODWARD, Kathryn. Identidade e diferença: uma introdução teórica e conceitual. In: Tomaz Tadeu da Silva (Org.). Identidade e diferença: a perspectiva dos estudos culturais. Petrópolis: Vozes, 2000. p. 7-68.

YOUNG, Iris Marion. Representação política, identidade e minorias. Lua Nova, São Paulo, n. 67, p. 139-190, $2006<10.1590 /$ S0102-64452006000200006>.

Recebido em: 3 abr. 2017

Aprovado em: 7 jul. 2017

Autora correspondente:

Luciana Garcia de Mello

Rua Gregório da Fonseca, 277 casa 2 - Nonoai

90830-260 Porto Alegre, RS, Brasil 